\title{
Augmentation of Morphine-Induced Sensitization but Reduction in Morphine Tolerance and Reward in Delta-Opioid Receptor Knockout Mice
}

\author{
VI Chefer*,' and TS Shippenberg' \\ 'Integrative Neuroscience Section, Behavioral Neuroscience Branch, National Institute on Drug Abuse, National Institutes of Health, Baltimore, \\ MD, USA
}

\begin{abstract}
Studies in experimental animals have shown that individuals exhibiting enhanced sensitivity to the locomotor-activating and rewarding properties of drugs of abuse are at increased risk for the development of compulsive drug-seeking behavior. The purpose of the present study was to assess the effect of constitutive deletion of delta-opioid receptors (DOPr) on the rewarding properties of morphine as well as on the development of sensitization and tolerance to the locomotor-activating effects of morphine. Locomotor activity testing revealed that mice lacking DOPr exhibit an augmentation of context-dependent sensitization following repeated, alternate injections of morphine (20 mg/kg; s.c.; 5 days). In contrast, the development of tolerance to the locomotor-activating effects of morphine following chronic morphine administration (morphine pellet: $25 \mathrm{mg}$ : 3 days) is reduced relative to WT mice. The conditioned rewarding effects of morphine were reduced significantly in DOPrKO mice as compared to WT controls. Similar findings were obtained in response to pharmacological inactivation of DOPr in WT mice, indicating that observed effects are not due to developmental adaptations that occur as a consequence of constitutive deletion of DOPr. Together, these findings indicate that the endogenous DOPr system is recruited in response to both repeated and chronic morphine administration and that this recruitment serves an essential function in the development of tolerance, behavioral sensitization, and the conditioning of opiate reward. Importantly, they demonstrate that DOPr has a distinct role in the development of each of these drug-induced adaptations. The anti-rewarding and tolerance-reducing properties of DOPr antagonists may offer new opportunities for the treatment and prevention of opioid dependence as well as for the development of effective analgesics with reduced abuse liability.
\end{abstract}

Neuropsychopharmacology (2009) 34, 887-898; doi:I0.1038/npp.2008. I28; published online I3 August 2008

Keywords: delta-opioid receptor; morphine; sensitization; tolerance; reward

\section{INTRODUCTION}

Opioid drugs are used clinically for the treatment of moderate-to-severe pain. They produce analgesia by the activation of mu-, delta-, or kappa-opioid receptors (MOPr, DOPr, and KOPr, respectively). Their chronic administration is associated with the development of tolerance and physical dependence. These consequences of chronic drug administration are limiting factors in the use of opiates for the management of pain (Bailey and Connor, 2005; Corbett et al, 2006).

Both analgesia and tolerance of the MOPr agonist, morphine, are abolished in MOPr knockout (KO) mice, indicating that the MOPr is essential for both of these effects

*Correspondence: Dr VI Chefer, Integrative Neuroscience Section, Behavioral Neuroscience Branch, NIDA/IRP, 333 Cassell Drive, Baltimore, MD 21224, USA, Tel: + 1410550 |451, Fax: + 410 550 1692, E-mail: vchefer@intra.nida.nih.gov

Received I 8 March 2008; revised 28 June 2008; accepted 30 June 2008
(Matthes et al, 1996; Sora et al, 1997). However, several lines of evidence suggest the involvement of the DOPr in morphine tolerance. Initial studies using DOPr antagonists (Abdelhamid et al, 1991) and more recent studies using DOPrKO mice (Zhu et al, 1999; Nitsche et al, 2002) showed that the development of morphine tolerance is attenuated in mice lacking functional DOPr. Importantly, however, although tolerance develops to other actions of morphine including its rewarding and locomotor-activating effects (Timar et al, 2005), only antinociception was assessed.

Acute MOPr agonist administration can increase or decrease locomotor activity depending on the dose administered and time of testing. Furthermore, chronic opioid treatment may result in tolerance or an augmentation (eg sensitization) of these effects. Tolerance and sensitization represent distinct forms of long-term plasticity that occur in response to continuous or repeated drug administration. Sensitization in rats can last as long as a year after the last administration of the drug, whereas tolerance is a more transient effect. Both phenomena have been implicated in 
the development and escalation of drug taking behavior (Robinson and Berridge, 1993; Zernig et al, 2007).

Highly selective DOPr antagonists such as naltrindole (NTI) and naltriben (NTB) do not suppress the antinociceptive effect induced by acute morphine administration (Narita et al, 1993). In contrast, both drugs significantly suppress morphine-induced hyperlocomotion in mice. They also attenuate increases in dopamine (DA) turnover (Narita et al, 1993) in the nucleus accumbens (NAc) that have been implicated in mediating the locomotor stimulant effects of opiates. These results suggest that DOPr contribute at least in part to the locomotor-activating and DA-releasing effects of MOPr agonists.

The mechanisms mediating functional interactions between DOPr and MOPr are not clear. However, heterodimerization of MOPr and DOPr has been reported in cell expression systems (Jordan and Devi, 1999; Law et al, 2005; Gupta et al, 2006). Evidence, that chronic morphine exposure promotes an increase in DOPr cell-surface expression has also been obtained (Cahill et al, 2001; Morinville et al, 2003).

Recently, Portoghese and coauthors (Daniels et al, 2005) described bivalent ligands composed of an MOPr agonist and a DOPr antagonist pharmacophore that target mu-/ delta-heterodimeric opioid receptors. These bivalent ligands suppressed physical dependence and tolerance without significantly compromising antinociceptive activity. Using the conditioned place preference (CPP) procedure, Lenard et al (2007) have shown that in contrast to morphine and other monovalent MOPr agonists, these bivalent ligands do not produce conditioned rewarding effects in mice. These findings are noteworthy in that they suggest that combined MOPr agonists/DOPr antagonists lack many side effects of conventional opioids.

Constitutive DOPr deletion has been used to examine the role of DOPr in the development of antinociceptive tolerance and physical dependence (Zhu et al, 1999; Nitsche et al, 2002). Surprisingly, there is no data in the literature regarding the influence of constitutive deletion of DOPr on the conditioned rewarding effects of MOPr agonists. Similarly, the role of DOPr in mediating the development of tolerance and sensitization to the locomotor-activating effects of MOPr agonists has not been assessed. Such information, however, is important in view of preclinical evidence that individuals exhibiting enhanced sensitivity to the locomotor-activating and rewarding properties of drugs of abuse are at increased risk for the development of compulsive drug-seeking behavior (Robinson and Berridge, 2000; Kornetsky, 2004; Hyman, 2005). Thus, the aim of the current studies was to determine whether constitutive deletion or pharmacological inactivation of DOPr affects the development of tolerance and sensitization to the locomotor-activating effects of morphine. The role of DOPr in mediating the conditioned rewarding effects of morphine was also examined.

\section{METHODS}

\section{Animals}

The generation of mice lacking DOPr has been previously described (Matthes et al, 1996; Filliol et al, 2000). Breeding pairs of homozygous KO mice, maintained on a pure C57BL/6 genetic background, were obtained from hybrid mutant mice (129 SVJ-C57BL/6 backgrounds) by backcrossing over 15 generations (CDTA, Orleans, France). Male offspring (3- to 4-month old) weighing 25-30 g were used as subjects. Additional studies were conducted in C57Bl/6J mice (25-30 g; Jackson Laboratory, Bar Harbor, ME, USA). Mice were housed 3-5 per cage in a temperature and humidity controlled environment with $12: 12 \mathrm{~h}$ light/dark cycle. Water and food were available ad libitum. Mice were allowed to habituate to the colony room for at least 7 days before the commencement of experiments. The animals were assigned randomly to different pretreatment groups (8-12 animals per group) within each genotype. Some animals were discarded due to equipment malfunctioning. The exact number of animals for each group is specified on each graph in the 'Results' section. All experiments took place during the light phase. All experimental procedures were conducted according to the National Institutes of Health Guide for the Care and Use of Laboratory Animals and were approved by the Animal Care and Use Committee of the National Institute on Drug Abuse (NIDA).

\section{Drugs}

Morphine hydrochloride and pellets containing morphine $(25 \mathrm{mg})$ or placebo were supplied by the Research Technology Branch of the NIDA (Rockville, MD, USA). Morphine hydrochloride was dissolved in sterile $0.9 \%$ saline. All doses refer to the base weight. The selective nonpeptide DOPr antagonist NTI hydrochloride (Portoghese $e t$ al, 1988) was obtained from Sigma (Sigma-Aldrich, St. Louis, MO, USA) and dissolved in sterile water.

\section{Experimental Procedures}

Sensitization to the locomotor-activating effect of morphine. Morphine injections: WT and KO mice received alternate day injections of morphine $(20 \mathrm{mg} / \mathrm{kg}, 0.1 \mathrm{ml}$ per $10 \mathrm{~g}$, s.c.) or saline $(0.1 \mathrm{ml}$ per $10 \mathrm{~g}$, s.c.) for 5 days in locomotor activity chambers (see below). Context-dependent behavioral sensitization was tested 7 and 33 days following the cessation of morphine administration. The challenge dose of morphine was $5 \mathrm{mg} / \mathrm{kg}$.

The DOPr antagonist NTI $(0.3 \mathrm{mg} / \mathrm{kg}$, s.c. $)$ was administered to WT mice $15 \mathrm{~min}$ before morphine injections to determine whether pharmacological blockade of DOPr produces effects similar to constitutive DOPr deletion. Locomotor activity in response to a challenge dose of morphine $(5.0 \mathrm{mg} / \mathrm{kg})$ was assessed on abstinence day 7 .

Locomotor activity test: Locomotor activity was measured in Plexiglas cages $(43 \times 44 \times 25 \mathrm{~cm})$ using an Opto-Varimex system (Columbus Instruments, Columbus, $\mathrm{OH}$ ). The horizontal sensor of the system consisted of two arrays of 15 infrared beams, which were perpendicular to each other. The beams were spaced $2.4-\mathrm{cm}$ apart. The Opto-Varimex was equipped with a Columbus Instruments data collection system and software package for an IBM computer (AutoTrack System V3.20A; Columbus Instruments). The location of an animal was read by the Auto-Track system 10x/s. The distance traveled by each animal during 5 min intervals was determined for each session. All animals were habituated 
for $2 \mathrm{~h}$ to the locomotor activity chambers 1 day before the commencement of the experiments. On the test or pretreatment days, animals were placed in the locomotor activity chambers and following a $1 \mathrm{~h}$ habituation period, baseline locomotor activity was measured for $2 \mathrm{~h}$. They were then injected with saline $(0.1 \mathrm{ml}$ per $10 \mathrm{~g}$, s.c.) and locomotor activity was measured for another $2 \mathrm{~h}$. Animals were then injected with morphine and activity was again measured for $2 \mathrm{~h}$. This design enabled within-group comparison of morphine-evoked locomotion to basal and saline-evoked locomotion and the assessment of treatment effects between groups.

\section{Tolerance to the Locomotor-Activating Effects of Morphine}

Morphine pellet implantation: Mice were anesthetized with isoflurane and implanted s.c. with one pellet containing 25-mg morphine or placebo. Pellets were removed under the same anesthesia 3 days later.

Locomotor activity test: Locomotor activity was quantified as described above $24 \mathrm{~h}$ following pellet removal.

\section{Morphine-Induced CPP}

CPP apparatus: Six CPP chambers, equipped with a matrix of photo beams spaced one inch apart and directed immediately above the surface of the floor, were used to measure automatically the locomotor activity and time spent in each compartment.

Each chamber was divided into three compartments: two conditioning compartments and one start compartment. The conditioning compartments were identical in size $(30 \times 30 \times 20 \mathrm{~cm})$ and had dark patterned walls. They were equipped with removable Plexiglas floors that differed in texture. One floor was smooth; the other was rough (raised diamond pattern). The start compartment $(20 \times 6 \times 20 \mathrm{~cm})$ had a gray smooth plastic floor. It contained two photo beams that when broken, activated the monitoring software. Animals were placed directly into this compartment for testing. All animals were tested in total darkness. The CPP procedure consisted of three phases: preconditioning, conditioning and postconditioning.

Preconditioning: For preconditioning, one compartment was equipped with the smooth floor and the other with the rough floor. On day 1, animals were habituated to the apparatus. They were placed in the gray compartment and allowed to explore the three compartments freely for $15 \mathrm{~min}$. On the following day (preconditioning, pretest), each mouse was again allowed free access to the compartments for $60 \mathrm{~min}$. Locomotor activity and time spent in each compartment were measured during this period. Animals that spent more than $85 \%$ of the time in one compartment were eliminated from the experiment. Preliminary studies demonstrated that naive WT animals spend ca. $50 \%$ of the time in each of the conditioning compartments indicating that the CPP procedure is unbiased in this genotype.

Conditioning: This phase consisted of a 6-day schedule of conditioning sessions (three saline, three morphine), each $60 \mathrm{~min}$ in duration. One conditioning session was conducted per day and the presentation order of morphine and saline was alternated. During this phase, both conditioning compartments were equipped with floors of the same texture (either smooth or rough) and animals were allowed free access to each. Half of the animals were injected with morphine and placed immediately in the smooth floor compartments whereas the other half were injected with saline was placed into the rough floor compartments. The presentation order of saline and morphine and floor pairing was counterbalanced within each genotype and treatment group. The doses of morphine (10 and $15 \mathrm{mg} / \mathrm{kg}$, s.c.) used for conditioning were those used in other studies (Cunningham et al, 1992). To determine whether pharmacological blockade of DOPr in WT mice produces effects similar to the results of constitutive deletion of DOPr, WT received the DOPr antagonist NTI $(0.3 \mathrm{mg} / \mathrm{kg}$, s.c.) $15 \mathrm{~min}$ before morphine $(10 \mathrm{mg} / \mathrm{kg}$; s.c.; 3 days $)$ and saline $(0.1 \mathrm{ml}$ per $10 \mathrm{~g}$; s.c.; 3 days) conditioning sessions.

Post-conditioning phase: Preference for the morphine- or saline-paired place was tested on day 8 by allowing uninjected mice free access to the three compartments for $60 \mathrm{~min}$ and measuring the time spent in each. As in the preconditioning test, one compartment contained the rough floor, whereas the other contained the smooth floor.

It has been shown that some effects of conditioning in mice can be missed completely if short test duration is used (Cunningham et al, 1998, 2003). The use of 60-min test sessions is appropriate in mouse CPP studies because mice, unlike rats, typically remain active throughout the test (Cunningham et al, 2003, 2006).

Data analysis: Horizontal locomotor activity expressed as distance traveled $(\mathrm{cm})$ was calculated in 5-min blocks. Total horizontal activities following injections of morphine or saline were converted to an area under the curve (AUC) values using a standard trapezoid method (Gibaldi and Perier, 1975). The resultant data were subjected to two-way repeated measures analyses of variances ANOVA (genotype: WT vs KO; drug: saline $v s$ morphine; days of pretreatment or days of abstinence) using SPSS and GraphPad Prizm software. Post hoc or simple main effect analyses were performed when the initial $p$ value was significant. Linear regression was plotted for AUC data and analyzed for slope difference between genotypes with GraphPad Prizm software. The CPP data were analyzed by two-way ANOVA (floor type: smooth vs rough; conditioning: pretest $v s$ posttest) and further analyses were conducted with post hoc tests when appropriate with SPSS software. The paired Student's $t$-test was used to analyze CPP data from experiments with unbiased design. The accepted value of significance for all tests was $p \leqslant 0.05$. The data are presented as mean \pm SEM.

\section{RESULTS}

\section{Effects of Constitutive DOPr Deletion on the Development and Expression of Context-Dependent Behavioral Sensitization to Morphine}

Figure 1 shows locomotor activity produced by morphine on days 1-5 of the morphine treatment regimen in WT and DOPrKO mice. There was a significant effect of genotype $\left(\mathrm{F}_{(1,16)}=5.4 ; p=0.04\right)$, but no significant drug $\times$ genotypes interaction $\left(\mathrm{F}_{(1,16)}=1.01 ; p=0.33\right)$ for the first day of treatment, indicating a larger locomotor responses to acute 

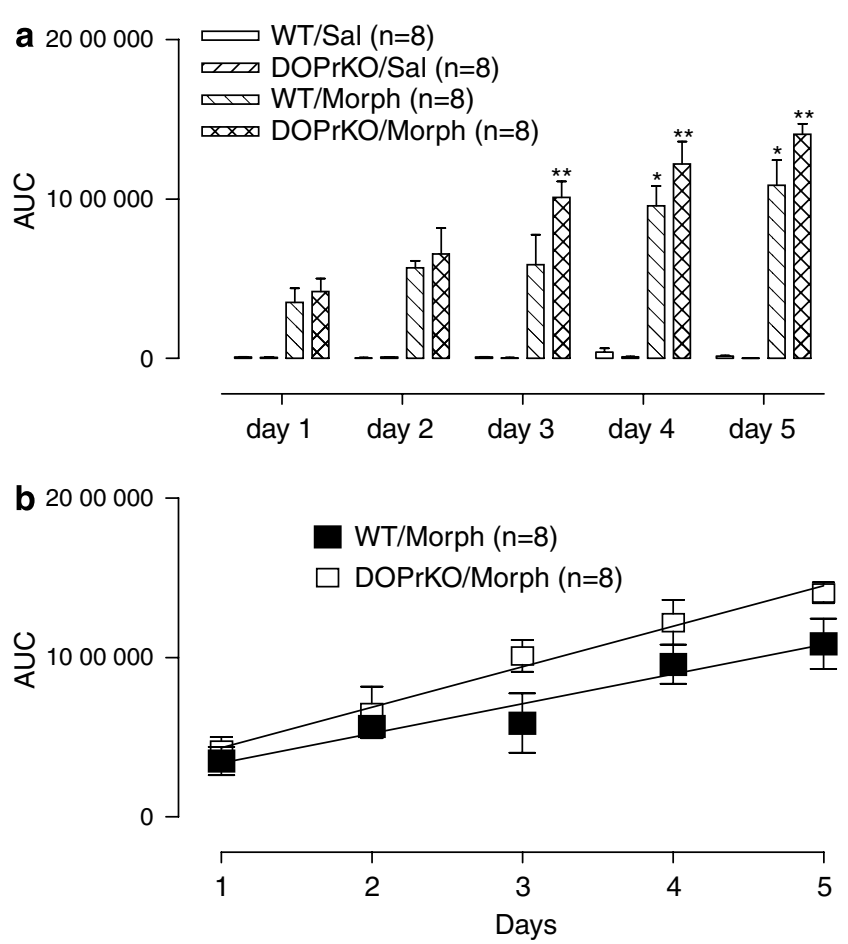

Figure I Development of context-dependent sensitization to morphine-induced hyperlocomotion in WT and DOPrKO mice. Mice were treated once a day every other day for 5 days in locomotor activity chambers with either two injections of saline $(0.1 \mathrm{ml}$ per $10 \mathrm{~g}$, s.c.) or saline followed by morphine $(20 \mathrm{mg} / \mathrm{kg}, 0.1 \mathrm{ml}$ per $10 \mathrm{~g}$, s.c.). (a) Area under the curve (AUC) values for morphine-evoked hyperlocomotion expressed as means \pm SEM (b) Linear regressions for the AUC values from $W T$ and $K O$ mice; *, significant difference from morphine-induced locomotor activity on the first day of treatment in WT mice; **, significant difference from morphine-induced locomotor activity on the first day of treatment in DOPrKO animals (Dunnett's multiple comparison test; see 'Results').

saline and morphine in DOPrKO. This finding is in agreement with previous data regarding the anxiogenic-like phenotype of DOPrKO mice (Filliol et al, 2000; Nieto et al, 2005; Roberts et al, 2001). A repeated measures ANOVA for all pretreatment days revealed significant main effects of genotype $\left(\mathrm{F}_{(1,28)}=6.5 ; \quad p=0.02\right)$, drug treatment $\left.\left(\mathrm{F}_{(1,28)}=241.4 ; p<0.01\right)\right)$ and treatment day $\left(\mathrm{F}_{(4,60)}=95.1\right.$; $p<0.01)$, as well as genotype $\times$ drug treatment $\left(\mathrm{F}_{(1,28)}=6.4\right.$; $p=0.02)$ and genotype $\times$ drug treatment $\times$ treatment day $\left(\mathrm{F}_{(4,60)}=5.2 ; p=0.01\right)$ interactions. This analysis indicates that morphine significantly increased locomotor activity relative to saline in both genotypes. However, there was a significant difference between genotypes; the response to morphine was significantly greater in DOPrKO mice. Moreover, this difference between genotypes was changing with treatment days. Although both genotypes exhibited context-dependent behavioral sensitization (morphine-induced locomotion was significantly higher on the fifth day compared with the first day: Dunnett's multiple comparison test $-\left(\mathrm{F}_{(4,39)}=9.1 ; p<0.01\right)$ and $\left(\mathrm{F}_{(4,29)}=8.9 ; p<0.01\right)$ for WT and DOPrKO, respectively), KO mice developed sensitization at a faster rate than the WT animals (Figure 1a). Thus, WT mice showed a sensitized response to morphine on treatment days 4 and 5 (Dunnett's multiple comparison test: $\left(\mathrm{F}_{(4,39)}=7.8 ; p<0.01\right)$ and $\left(\mathrm{F}_{(4,39)}=9.1\right.$; $p<0.01$ ), respectively), whereas $\mathrm{KO}$ animals showed an augmented response to morphine on days 3-5 (Dunnett's multiple comparison test: : $\left(\mathrm{F}_{(4,39)}=5.3 ; p<0.01\right)$, $\left(\mathrm{F}_{(4,39)}=7.2 ; p<0.01\right)$ and $\left.\left(\mathrm{F}_{(4,39)}=8.9 ; p<0.01\right)\right)$. Analysis of the slopes obtained by linear regression of the AUC values for the two genotypes also confirmed that the rate in which sensitization developed was significantly greater in KO mice (Figure 1b; $185800 \pm 26260$ in WT $v s$ $253600 \pm 16780$ in KO; $\left.\mathrm{F}_{(1,6)}=4.9 ; p=0.05\right)$.

Figure 2 shows time course and AUC data for locomotor activity during saline and morphine challenge on abstinence days 7 and 33. Morphine-evoked locomotor activity was significantly greater in $\mathrm{KO}$ as compared to WT mice on abstinence day $7 \quad\left(\mathrm{~F}_{(1,9)}=8.6 ; p=0.03\right)$. No difference between genotypes was apparent on day $33\left(\mathrm{~F}_{(1,9)}=0.6\right.$; $p=0.96$ ), indicating that the expression of context-dependent behavioral sensitization is augmented in DOPrKO mice at early but not later stages of abstinence.

To determine whether pharmacological blockade of DOPr in WT mice produces similar effects, WT mice received the DOPr antagonist NTI $(0.3 \mathrm{mg} / \mathrm{kg}$, s.c. $) 15 \mathrm{~min}$ before the alternate day injections of morphine. Morphine-evoked locomotor activity was then assessed on abstinence day 7 (Figure 3). Two-factor ANOVA revealed a significant main effect of morphine treatment $\left(\mathrm{F}_{(1,30)}=14.1 ; p<0.01\right)$ and a significant $\mathrm{NTI} \times$ morphine interaction $\left(\mathrm{F}_{(1,30)}=3.7\right.$; $p=0.05)$. Probing of the interaction revealed significant effects of NTI in morphine- $\left(\mathrm{F}_{(1,15)}=4.0 ; p=0.05\right)$, but not saline-treated animals $\left(\mathrm{F}_{(1,15)}=0.1 ; p=0.77\right)$, indicating that sensitization to the locomotor-activating effects of morphine is enhanced in mice that had received morphine previously with a DOPr antagonist.

\section{Effects of Constitutive DOPr Deletion on the Expression of Tolerance to the Locomotor-Activating Effects of Morphine}

Figure 4 shows that regardless of genotype, chronic morphine administration produces tolerance to its locomotor-activating effects. ANOVA revealed significant main effect of morphine pretreatment $\left(\mathrm{F}_{(1,21)}=35.8 ; p<0.01\right)$ and genotype $\left(\mathrm{F}_{(1,21)}=4.3 ; p=0.05\right)$, but no interaction $\left(\mathrm{F}_{(1,21)}=0.9 ; p=0.35\right)$. The locomotor response to the morphine challenge was reduced in morphine-pelleted mice regardless of genotype. However, the decrease in activity was significantly smaller in DOPrKO mice $\left(\mathrm{F}_{(1,11)}=63.4\right.$; $p<0.01)$. Morphine-evoked locomotion was almost completely blocked in WT animals and only reduced slightly in DOPrKO mice, indicating suppression of behavioral tolerance to morphine in DOPrKO animals.

\section{Effects of Constitutive DOPr Deletion on the Conditioned Rewarding Effects of Morphine}

The mean time spent in each compartment during the pretest is shown in Figure 5 as a function of genotype. There was no difference in pretest data between the two doses of morphine (10 and $15 \mathrm{mg} / \mathrm{kg}$, s.c.) within each genotype (WT, $10 \mathrm{mg} / \mathrm{kg}$, rough $v s$ smooth: $1697.06 \pm 122.53$ vs $1662.01 \pm 128.18 ; \quad 15 \mathrm{mg} / \mathrm{kg}$, rough $v s$ smooth: $1657.22 \pm 133.91$ vs $1642.55 \pm 130.05 ; \mathrm{KO}, 10 \mathrm{mg} / \mathrm{kg}$, rough vs smooth: $1959.45 \pm 76.77$ vs $1380.66 \pm 90.59 ; 15 \mathrm{mg} / \mathrm{kg}$, rough $v s$ smooth: $1926.05 \pm 82.99$ vs $1335.81 \pm 66.82$ ). 

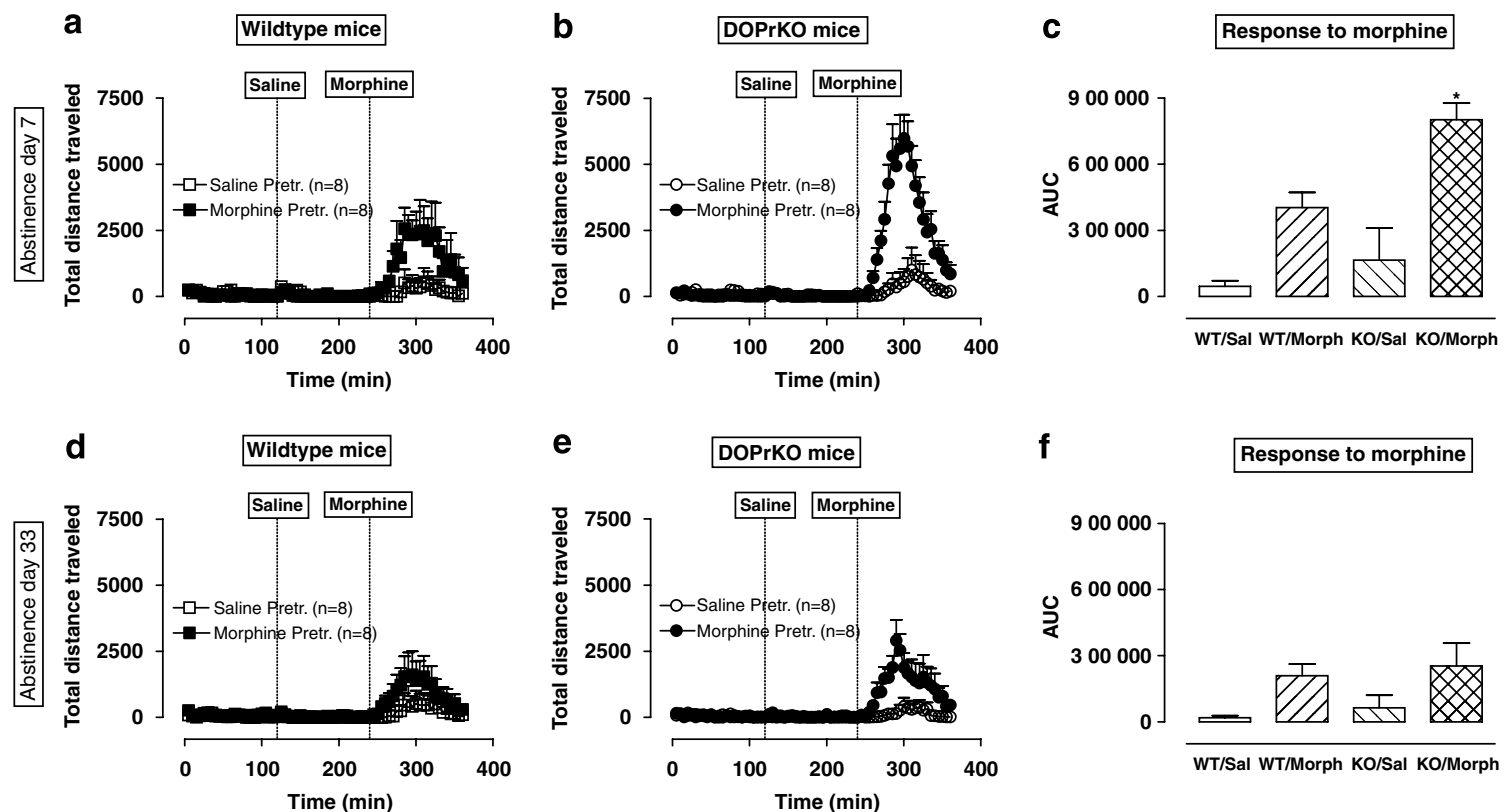

Figure 2 Expression of context-dependent behavioral sensitization is augmented in DOPrKO on abstinence day 7 (a-c). There is no difference between genotypes on abstinence day $33(\mathrm{~d}-\mathrm{f})$. (a, b) Time course of locomotor activity before and after injections of saline and morphine (5 mg/kg) in WT (a) and $\mathrm{KO}$ (b) mice on abstinence day 7. Each data point represents the mean ( \pm SEM) of the distance traveled during I0-min interval from eight animals. Abscissa: time in min. Vertical dotted lines correspond to the time of saline and/or morphine injections. Other details as in Figure I. (c) Area under the curve (AUC) values for morphine-evoked hyperlocomotion expressed as means \pm SEM; *, significant difference between WT and DOPrKO morphine-treated mice (Tukey's post hoc testl; see 'Results'). (d, e) Time course of locomotor activity before and after injections of saline and morphine (5 mg/kg) in WT (d) and KO (e) mice on abstinence day 33. Other details as in (a) and (b). (f) (AUC) values for morphine-evoked hyperlocomotion expressed as means \pm SEM.

Therefore, these data were pooled within each genotype for subsequent statistical analysis of the pretest information only.

Two-factor ANOVA revealed a significant difference between genotypes in initial floor preference $\left(\mathrm{F}_{(1,81)}=23.0\right.$; $p<0.01)$, no significant effect of genotype $\left(\mathrm{F}_{(1,81)}=0.4\right.$; $p=0.9$ ), and a significant floor $\times$ genotype interaction $\left(\mathrm{F}_{(1,81)}=11.1 ; p<0.01\right)$. Post hoc analysis revealed a significant effect of floor type in $\mathrm{KO} \quad\left(\mathrm{F}_{(1,43)}=56.0\right.$; $p<0.01)$ but not WT mice $\left(\mathrm{F}_{(1,37)}=0.7 ; p=0.4\right)$. These findings indicate that in contrast to WT mice that spent equal time in the smooth and rough floor compartments (Figure 5a), KO animals exhibited a significant preference for the rough floor compartment (Figure 5b). In view of this initial bias, the results of CPP experiments within each genotype were analyzed as a function of floor assignment.

Figure 6 shows the pre- (A) and posttest (B) data obtained in CPP experiments with $10 \mathrm{mg} / \mathrm{kg}$ morphine in WT mice. These animals spent equal time in each of the conditioning compartments during pretest $\left(\mathrm{F}_{(1,23)}=0.104 ; p=0.75\right)$, indicating that the CPP procedure was unbiased for this genotype. The repeated measures ANOVA (saline $v s$ morphine pairing; pretest $v s$ posttest) revealed a significant main effect of drug pairing $\left(\mathrm{F}_{(1,23)}=17.3 ; p<0.01\right)$ and a significant drug $\times$ pre- $v s$ posttest interaction $\left(\mathrm{F}_{(1,23)}=12.4\right.$; $p=0.02$ ). Analysis of the interaction revealed a significant increase in time spent during posttest in the morphinepaired compartment as compared to the pretest $\left(\mathrm{F}_{(1,11)}=4.7 ; p=0.05\right)$ or saline-paired compartment during posttest $\left(\mathrm{F}_{(1,23)}=61.9 ; p<0.01\right)$, indicating that WT mice exhibited a significant morphine-induced place preference regardless of the contextual cue employed. Similar results were obtained for the $15 \mathrm{mg} / \mathrm{kg}$ dose of morphine with significantly greater time spent in the morphine-paired compartment as compared with the saline-paired $\left(\mathrm{F}_{(1,22)}=16.7 ; p<0.01\right)$ or relative to pretest $\left(\mathrm{F}_{(1,10)}=4.1\right.$; $p=0.05)$.

Figure 7 shows time spent by DOPrKO mice in each compartment during the pre- and posttest in experiments with $10 \mathrm{mg} / \mathrm{kg}$ of morphine. $\mathrm{KO}$ animals exhibit a significant initial place preference for the rough floor during pretest $\left(\mathrm{F}_{(1,20)}=36.4 ; p<0.01\right)$, indicating that the CPP procedure was biased for this genotype. The two way repeated measures ANOVA (saline $v s$ morphine pairing; smooth $v s$ rough floor; pretest $v s$ posttest) revealed a significant effect of floor type $\left(\mathrm{F}_{(1,20)}=16.7 ; p=0.01\right)$, no significant effect of drug pairing $\left(\mathrm{F}_{(1,20)}=0.09 ; p=0.92\right)$, and a significant floor $\times$ pre- $v s$ post-interaction $\left(\mathrm{F}_{(1,24)}=10.6\right.$; $p=0.04$ ). Subsequent analysis revealed that morphine was ineffective as a conditioning drug when paired with the preferred rough floor $\left(\mathrm{F}_{(1,10)}=0.12 ; p=0.74\right)$. However, when morphine was paired with the smooth floor, time spent in the smooth floor compartment increased relative to the time spent there during pretest $\left(\mathrm{F}_{(1,5)}=7.9 ; p=0.04\right)$. Similar results were obtained with the higher dose of morphine $(15 \mathrm{mg} / \mathrm{kg})$. Animals showed an initial place preference for the rough floor $\left(\mathrm{F}_{(1,21)}=21.5\right.$; $p<0.01)$ and an increase in time spent in the less preferred compartment paired with morphine $\left(\mathrm{F}_{(1,5)}=6.1 ; p=0.048\right)$. These results indicate that DOPrKO exhibit a significant initial place preference and significant morphine-induced place preference when the drug was paired with the less preferred floor. Initial avoidance of the smooth floor by DOPrKO mice correlates with the anxiogenic phenotype described for these animals (Filliol et al, 2000; Nieto et al, 2005; Roberts et al, 2001); as in many cases with initial 

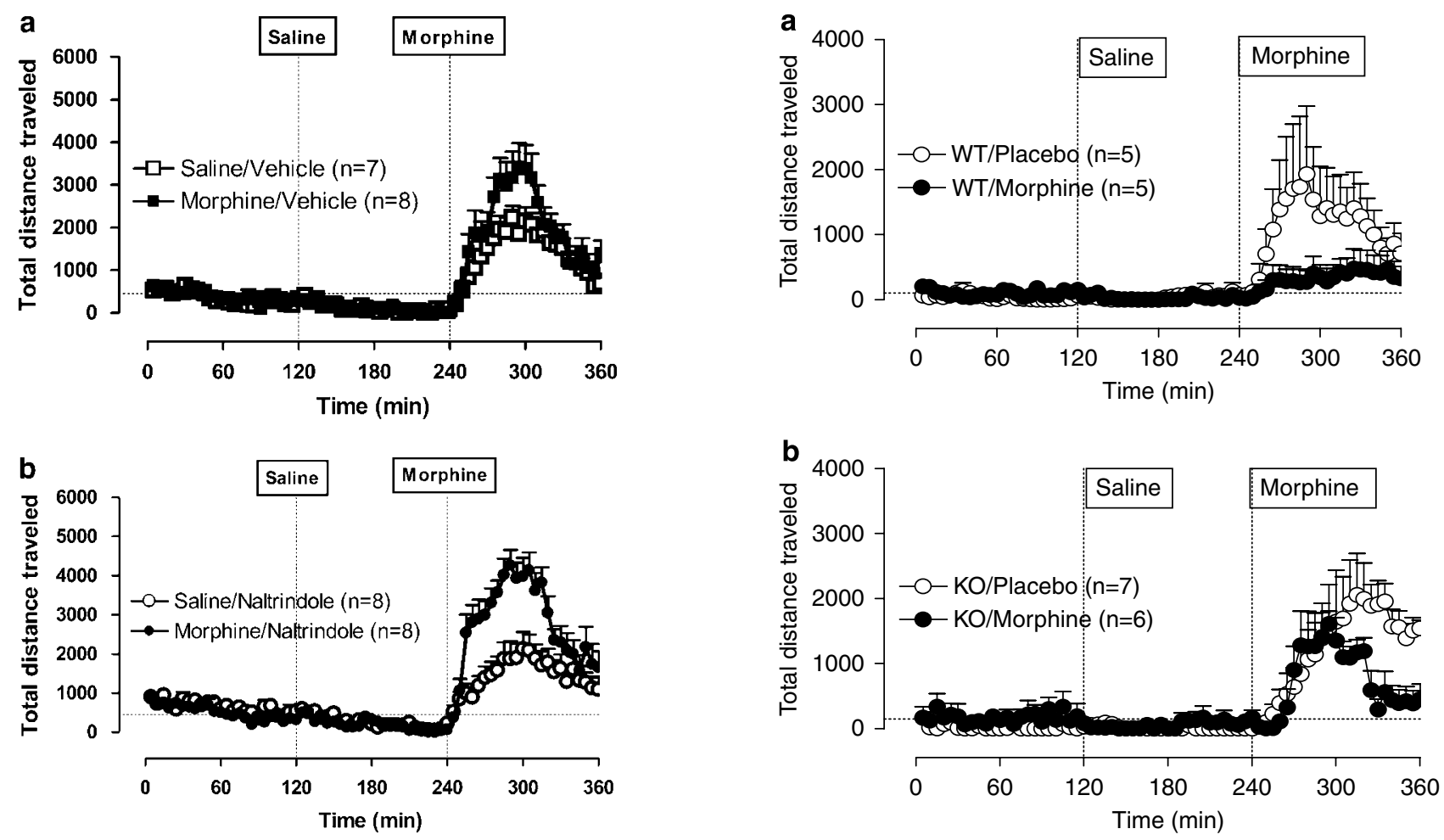

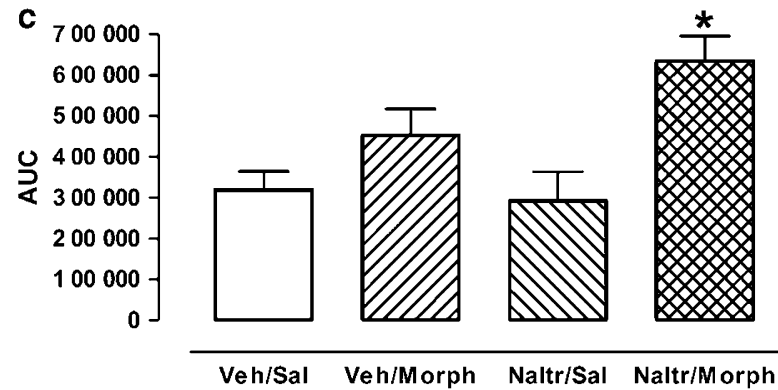

Figure 3 Expression of behavioral sensitization is augmented in WT mice pretreated with the selective DOPr antagonist naltrindole. (a) Time course of locomotor activity before and after injections of saline $(0.1 \mathrm{ml}$ per $10 \mathrm{~g}$, s.c.) and morphine (0.1 ml per 10 g, s.c.; $5 \mathrm{mg} / \mathrm{kg}$ ) and morphineinduced hyperlocomotion expressed as area under the curve (AUC) (b) for animals treated previously with vehicle $(0.05 \mathrm{ml}$ per 10 g, s.c.) $15 \mathrm{~min}$ before either saline ( $0.1 \mathrm{ml} / \mathrm{kg}$, s.c.) or morphine $(20 \mathrm{mg} / \mathrm{kg}, 0.1 \mathrm{ml} / \mathrm{kg}$, s.c.) every other day for 5 days. (c) Time course of locomotor activity before and after injections of saline ( $0.1 \mathrm{ml}$ per 10 g, s.c.) and morphine $(0.1 \mathrm{ml}$ per $10 \mathrm{~g}$, s.c.; $5 \mathrm{mg} / \mathrm{kg}$ ) and morphine-induced hyperlocomotion expressed as AUC (d) for animals previously treated with naltrindole $(0.3 \mathrm{mg} / \mathrm{kg}, 0.05 \mathrm{ml}$ per 10 g, s.c.) $15 \mathrm{~min}$ before either saline $(0.1 \mathrm{ml} / \mathrm{kg}$, s.c.) or morphine $(20 \mathrm{mg} / \mathrm{kg}, 0.1 \mathrm{ml} / \mathrm{kg}, \mathrm{s.c}$.) every other day for 5 days. Other details as in Figures I and 2; *, significant difference between vehicle/morphine and naltrindole/morphine groups (Tukey's post hoc test; see 'Results').

avoidance (Schenk et al, 1985; Carr et al, 1989; Swerdlow et al, 1989), one can assume that any improvement following drug pairing with the less preferable conditions is not due to the rewarding, but to anxiolytic properties of the drug.

As the differential effects of morphine in the two genotypes could reflect the use of a biased design in KO mice, additional studies were undertaken to establish conditions resulting in an unbiased design in KO mice. As shown in Figure 8c, when clean hardwood laboratory

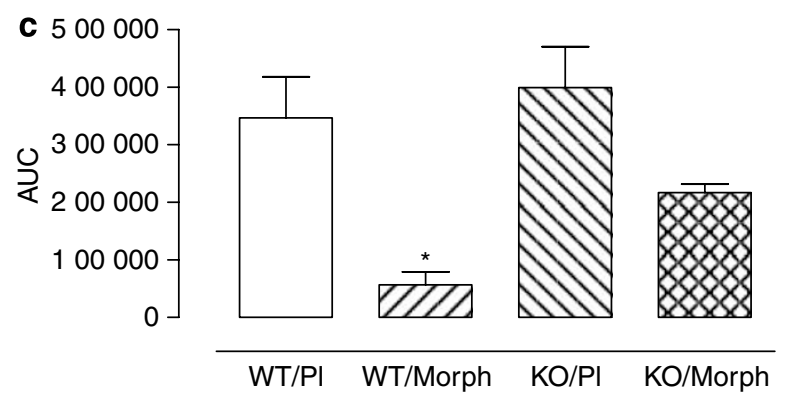

Figure 4 Reduction of tolerance to the locomotor-activating effects of morphine in DOPrKO mice. (a) Time course of locomotor activity before and after injections of saline and morphine $(5 \mathrm{mg} / \mathrm{kg})$ and morphineinduced hyperlocomotion expressed as area under the curve (AUC) (b) for WT animals ( $n=7-8$ ) treated previously with morphine (one $25 \mathrm{mg}$ pellet) or placebo (one pellet) for 3 days. (c) Time course of locomotor activity before and after injections of saline and morphine $(5 \mathrm{mg} / \mathrm{kg}$ ) and morphine-induced hyperlocomotion expressed as AUC (d) for DOPrKO animals treated previously with morphine (one $25 \mathrm{mg}$ pellet) or placebo (one pellet) for 3 days. Other details as in Figures I and 2; *, significant difference between WT and DOPrKO mice treated with morphine pellets (Tukey's post hoc test; see 'Results').

bedding (Beta chip; $3 \mathrm{ml}$ ) was placed on the smooth floor, KO mice exhibited no preference for either the rough or modified smooth floor $(t=0.7$; d.f. $=22 ; p=0.49)$. WT animals showed some initial preference to the smooth floor (Figure 8a). However, the difference between time spent in the rough and smooth floor compartments was not statistically significant $(t=1.57$; d.f. $=22, p=0.13)$. When experiments with morphine were conducted using these conditions, results analogous to those acquired using a biased design were obtained. Morphine produced conditioned rewarding effect in WT mice after six (three morphine, three saline) conditioning sessions (Figure 8b; $t=2.61 ;$ d.f. $=22, p=0.01)$. Conversely, there was no 

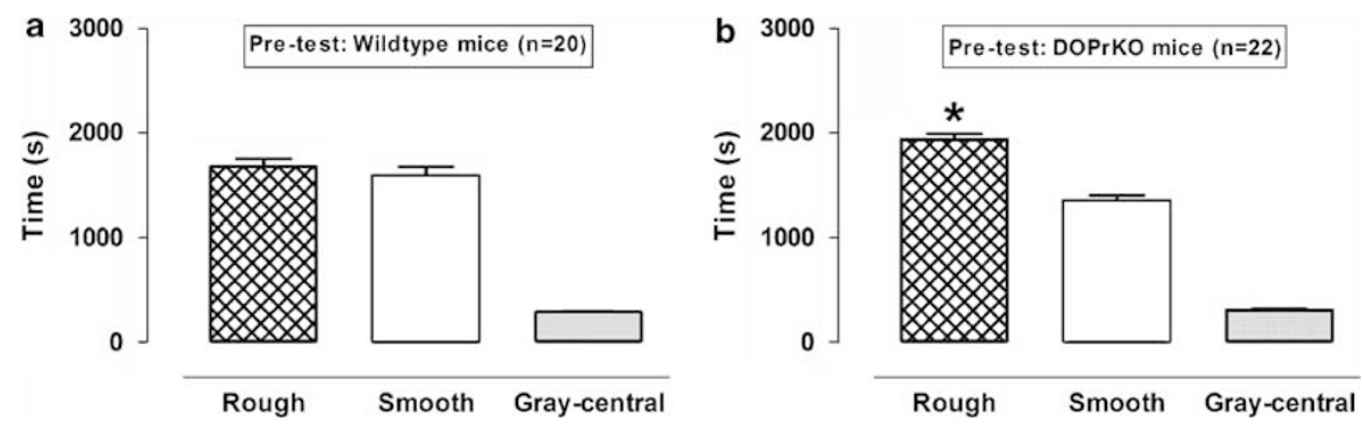

Figure 5 WT mice demonstrate no place preference during the pretest, whereas DOPrKO show a significant preference for the rough floor compartment. The data are expressed as mean ( \pm SEM) time spent in each compartment during the pretest for WT (a) and KO (b) animals; *, significant difference between time spent in rough and smooth floor compartments in DOPrKO animals (Tukey's post hoc test; see 'Results').
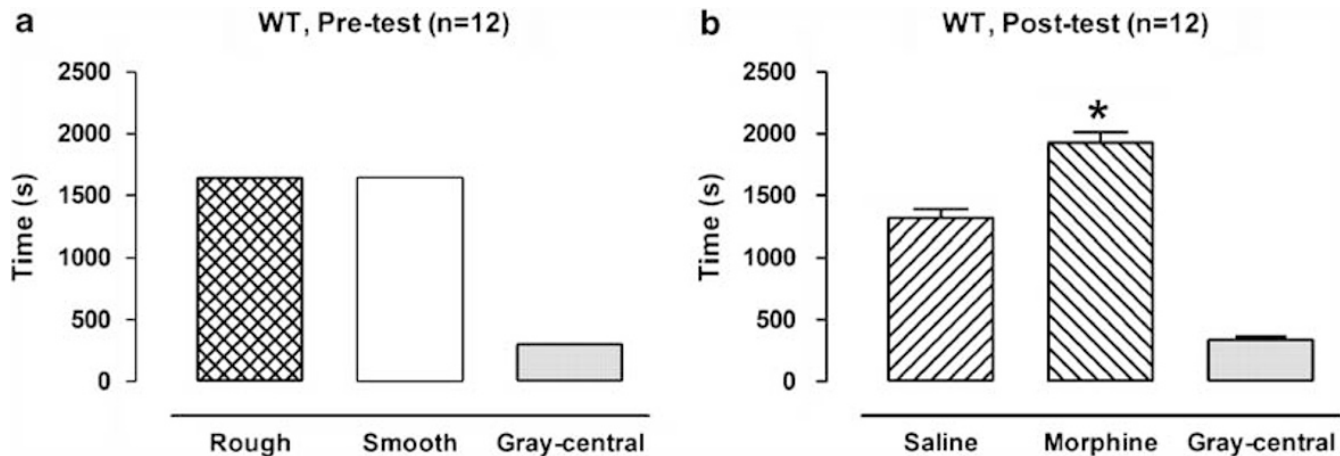

Figure 6 WT animals exhibit a significant conditioned place preference for the morphine-associated compartment. The data are expressed as mean of the time spent in each compartment during pre- (a) and post- (b) tests \pm SEM; *, significant difference between time spent in saline and morphine-paired compartments during post test (Tukey's post hoc test; see 'Results'). Morphine dose was $10 \mathrm{mg} / \mathrm{kg}$.

significant morphine-induced place preference following six conditioning sessions (Figure $8 \mathrm{~d} ; t=1.9$, d.f. $=22$, $p=0.07)$ in DOPrKO animals. To determine whether morphine can produce a conditioned response if the number of environmental pairings is increased, two additional conditioning sessions were conducted and animals were then retested. The results show a significant morphine-induced place preference (Figure $8 \mathrm{~d} ; t=2.03$, d.f. $=22, p=0.05)$ in DOPrKO animals that had received eight conditioning sessions. Taken together, these results indicate that DOPrKO mice showed lesser ability to acquire morphine-induced place preference; however, place preference can be obtained with an increase in conditioning sessions.

To determine whether pharmacological blockade of DOPr in WT mice produces similar effects, WT received the DOPr antagonist NTI $(0.3 \mathrm{mg} / \mathrm{kg}$, s.c.) $15 \mathrm{~min}$ before morphine $(10 \mathrm{mg} / \mathrm{kg}$, s.c.) and saline $(0.1 \mathrm{ml}$ per $10 \mathrm{~g}$, s.c.) conditioning sessions (Figure 9). Administration of NTI alone was ineffective as a conditioned stimulus $\left(\mathrm{F}_{(1,11)}=1.15\right.$; $p=0.08$ ). Although morphine produced significant conditioning in vehicle-pretreated mice following six conditioning sessions (morphine-paired place: $2015 \pm 129 \mathrm{~s}$; saline-paired place: $1507 \pm 115 \mathrm{~s} ; t=2.9, \quad$ d.f. $=10$, $p=0.015)$, no CPP was apparent in mice that had received morphine in combination with NTI $(1726 \pm 113 \mathrm{~s} v \mathrm{~s}$ $1546 \pm 80 \mathrm{~s} ; t=1.31$, d.f. $=10, p=0.22$ ), indicating that development of morphine-induced CPP can be prevented by NTI.

\section{DISCUSSION}

The present study shows that mice lacking DOPr exhibit an augmentation of context-dependent sensitization and a significant reduction in tolerance to the locomotor-activating effects of morphine. Lack of functional DOPr is also associated with a reduction in the conditioned rewarding effects of morphine.

Chronic morphine administration may result in tolerance or sensitization to the locomotor-activating effects of the drug depending on the dose, frequency of administration, treatment duration, and duration of abstinence (Eitan et al, 2003; Contet et al, 2007). To assess the role of DOPr in these drug-induced forms of long-term plasticity, we used two distinct morphine pretreatment protocols to induce behavioral sensitization and tolerance. As environmental cues associated with drug administration have been implicated in the development of sensitization and compulsive drugseeking (Zernig et al, 2007), a context-dependent sensitization protocol was employed.

Consistent with the anxiogenic-like phenotype of DOPrKO mice (Filliol et al, 2000; Nieto et al, 2005; Roberts et al, 2001), DOPrKO mice showed a greater locomotor response to an acute injection of saline relative to WT controls. Regardless of genotype, alternate-day injections of morphine produced a marked enhancement of drug-induced locomotor activity that was still apparent 7 but not 33 days after the cessation of the repeated morphine treatment regimen. However, the magnitude of sensitization and the 

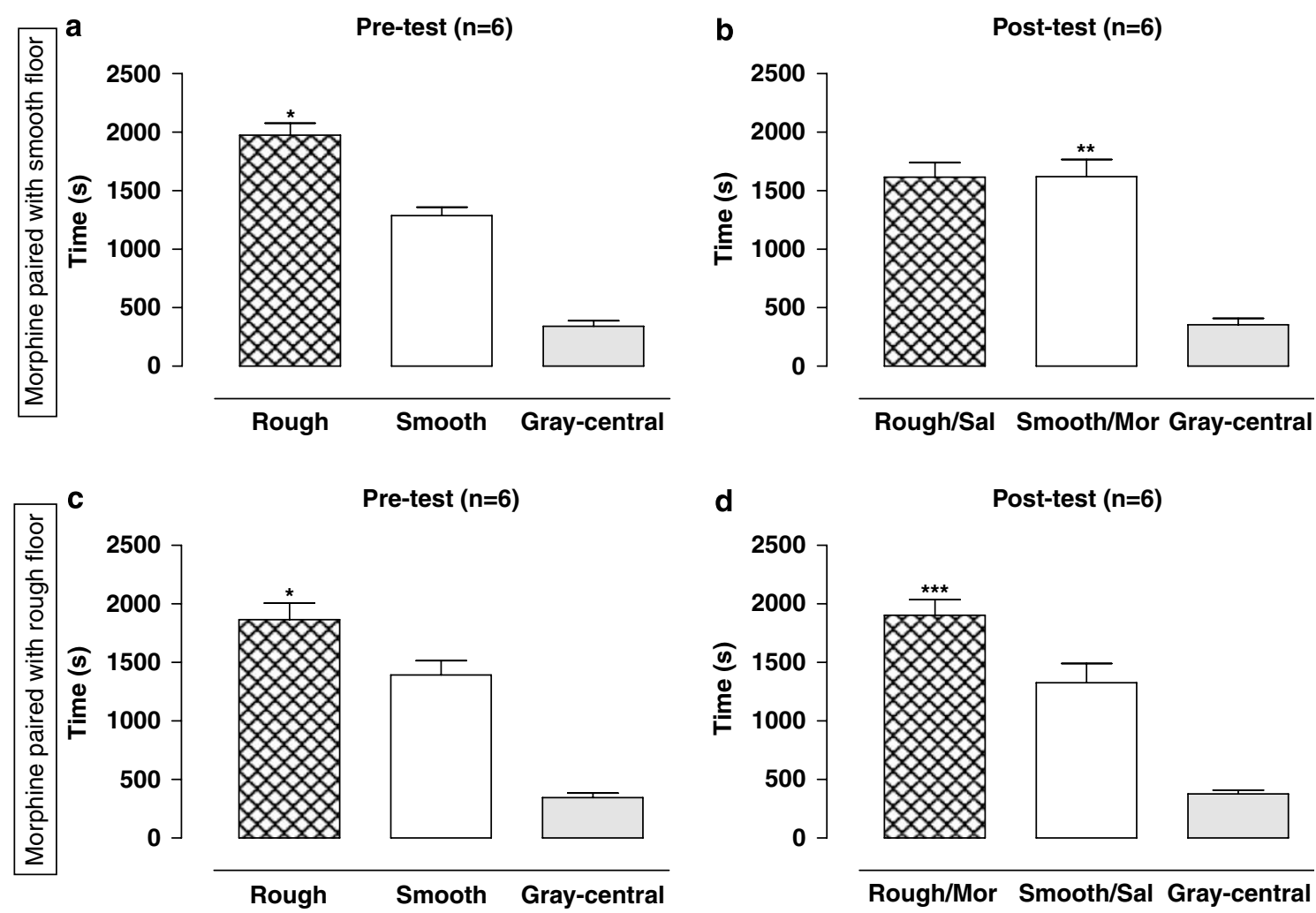

Figure 7 DOPrKO mice show an initial place preference during pretest and decreased conditioned response to morphine. The data are expressed as mean time spent in each compartment during pre- $(a, c)$ and post- $(b, d)$ tests \pm SEM. $(a, b)$ The results of experiments, when morphine was paired with the smooth floor; (c, d) - the results of experiments, when morphine was paired with the rough floor; *, significant difference between time spent in rough and smooth floor compartments during pretest (Tukey's post hoc test; see 'Results'); **, significant difference between time spent in morphine-paired smooth compartments during pre- and posttest (Tukey's post hoc test); ****, significant difference between time spent in saline- and morphine-paired compartments during posttest (Tukey's post hoc test; see 'Results'). Morphine dose was $10 \mathrm{mg} / \mathrm{kg}$.

rate of its development were augmented in DOPrKO animals. These results provide the first demonstration that the acquisition and short-term expression of morphineinduced behavioral sensitization is augmented in animals lacking DOPr. An augmented response to morphine was also observed in WT mice that had received the morphine treatment regimen in combination with the DOPr antagonist NTI. As such, the results obtained in DOPrKO mice cannot be attributed to developmental compensations resulting from constitutive DOPr deletion. Together, these data highlight the involvement of DOPr in the development of behavioral sensitization and suggest that a decrease in DOPr activity is associated with increased sensitization to the locomotor-activating effects of morphine.

The mechanisms mediating the augmentation of sensitization are unclear. Previous characterization of DOPrKO mice revealed a widespread downregulation of $\mathrm{MOPr}$ expression in the brain (Goody et al, 2002). Thus, a decrease in the behavioral effects of morphine would have been anticipated. On the other hand, binding studies (Goody et al, 2002; Simonin et al, 2001) have shown a downregulation of KOPr in DOPrKO mice. KOPr activation prevents the development of behavioral sensitization to cocaine (Heidbreder et al, 1993; Heidbreder and Shippenberg, 1994; Schenk et al, 2001). Moreover, pharmacological blockade of $\mathrm{KOPr}$ by the selective antagonist nor-BNI significantly increase sensitization to the locomotor-activating and DA-releasing effects of morphine (Spanagel and Shippenberg, 1993). Consequently, downregulation of KOPr in DOPrKO mice may underlie the enhanced sensitized response to morphine in KO mice. Importantly, however, an augmentation of sensitization was also observed in WT mice that received NTI in combination with morphine. Therefore, it appears unlikely that KOPr-downregulation is just the result of developmental compensation to genetic deletion of DOPr. This downregulation may actually reflect the intricate role of $\mathrm{DOPr}$ and $\mathrm{KOPr}$ interaction in mechanisms underlying behavioral sensitization.

Another form of drug-induced adaptation is tolerance. The results of the present study revealed a significant reduction in tolerance to the locomotor-activating effects of morphine in DOPrKO mice. These findings extend those showing that morphine analgesic tolerance does not develop in either DOPr (Zhu et al, 1999) or preproenkephalin (Clarke et al, 2002) KO mice. Furthermore, they are in line with the findings showing that DOPr antagonists (Abdelhamid et al, 1991; Miyamoto et al, 1993; Fundytus et al, 1995) and novel opioid compounds with mixed MOPr agonist/ DOPr antagonist properties (Schiller et al, 1999; Wells et al, 2001; Daniels et al, 2005) reduce analgesic tolerance to morphine. The mechanisms underlying opioid tolerance are not fully understood. Studies in cell-expression systems have suggested that a physical interaction between MOPr and DOPr may be an important factor in the development 

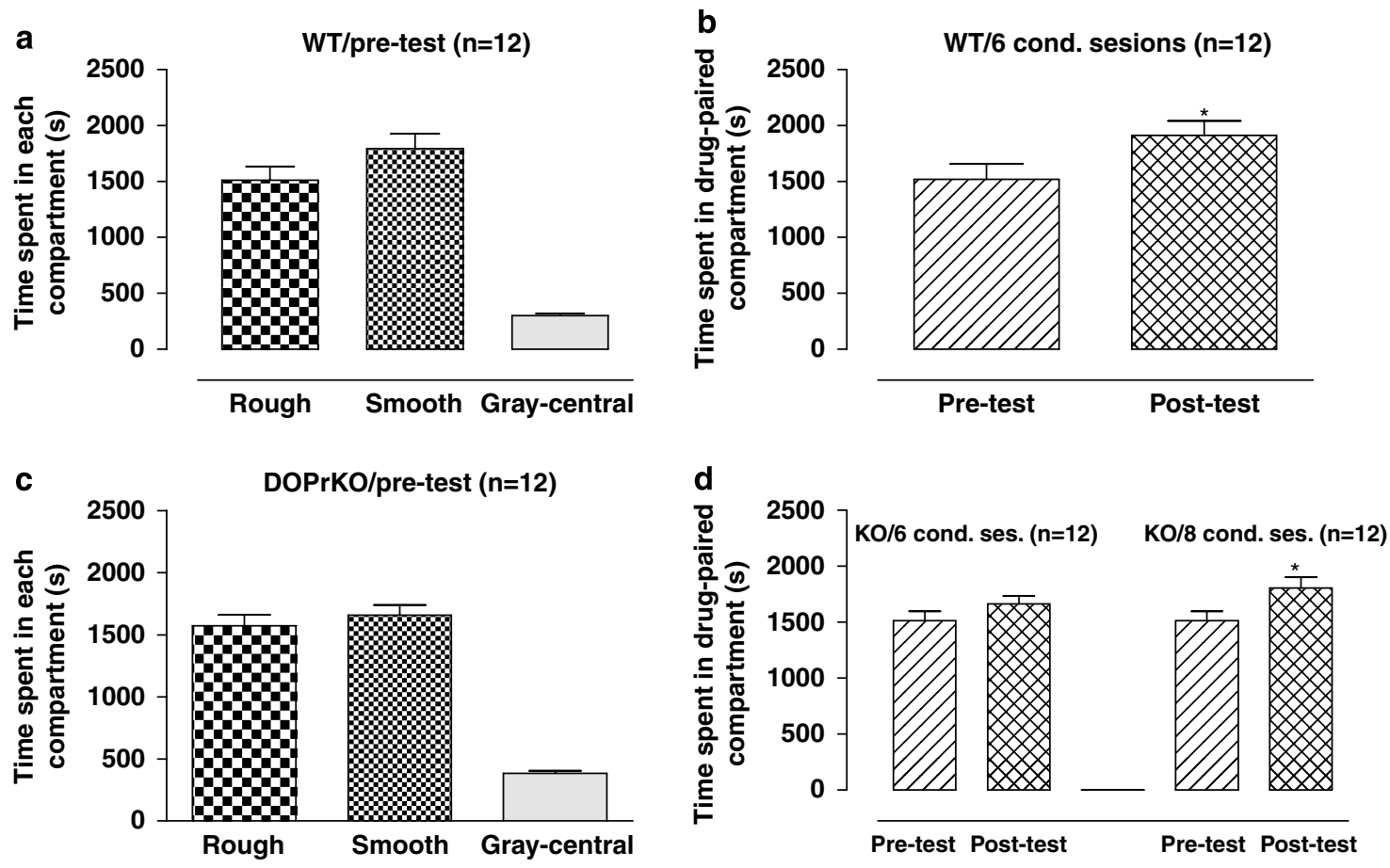

Figure 8 Morphine can produce a conditioned response in DOPrKO with increased number of environmental pairings in unbiased conditions. The data are expressed as mean \pm SEM of the time spent in each compartment during pretest ( $a, c)$ and time spent in reinforced compartments (pre- $v s$ posttest; $b$, $d$ ) for WT $(a, b)$ and DOPrKO animals (c, d); *, significant difference between time spent in morphine-paired compartments during pre- and posttest (paired t-test; see 'Results'). In contrast to the results presented in Figure 7, an unbiased place conditioning procedure was employed (see 'Methods'). Morphine dose was $10 \mathrm{mg} / \mathrm{kg}$.
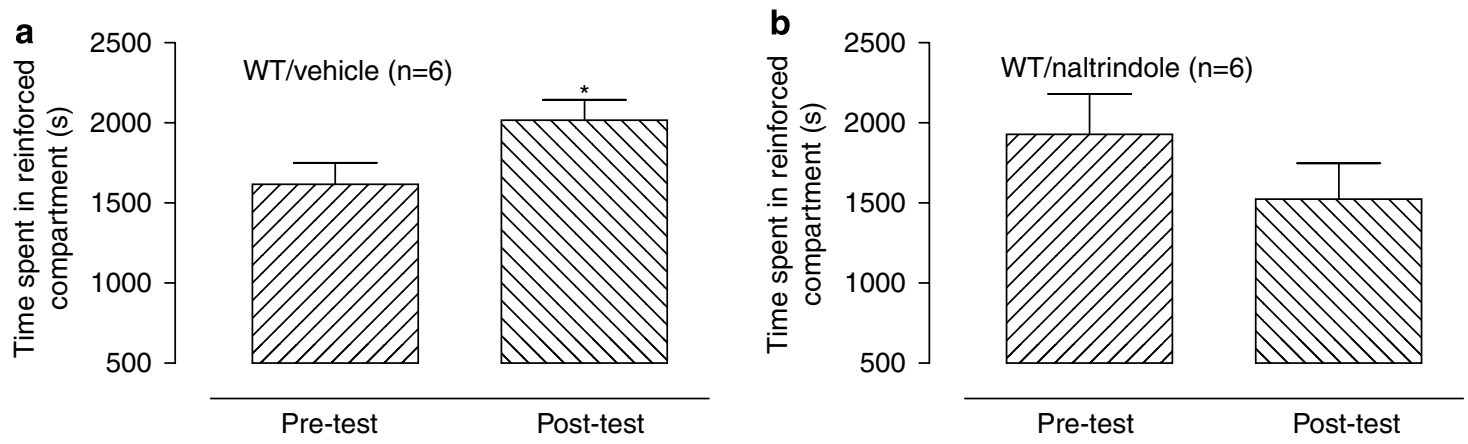

Figure 9 Morphine-induced conditioned place preference (CPP) is abolished in WT mice pretreated with the selective DOPr antagonist naltrindole. The data are expressed as mean \pm SEM of time spent in reinforced compartments (pre- vs posttest) for WT mice pretreated with vehicle (a) and WT mice pretreated with naltrindole (b); *, significant difference between pre- and posttest time for WT mice treated with vehicle (Tukey's post hoc test; see 'Results'). Morphine dose was $10 \mathrm{mg} / \mathrm{kg}$.

of tolerance (Rozenfeld et al, 2007). It has been reported that chronic morphine treatment increases the surface expression of DOPr by selective activation of $\mathrm{MOPr}$ (Morinville et al, 2003, 2004). Additional studies are needed to determine whether either or both mechanisms underlie the effects observed in this and previous behavioral studies.

DOPrKO mice developed a place preference to morphine when the drug was paired with the nonpreferred floor and failed to develop it when the drug was paired with the preferred floor, whereas WT controls exhibited robust preferences in the same experimental conditions. The absence of conditioning in DOPrKO mice when drug was paired with the initially preferred floor can be interpreted as a 'ceiling' effect, not an indication of the reduced rewarding properties. However, the present findings suggest that the lack of conditioning is the result of the rewarding effects of morphine and not the result of a 'ceiling' effect, because WT animals in the biased conditions, created with the laboratory bedding, did show a robust conditioning when morphine was paired with both the nonpreferred and preferred floor. Moreover, when unbiased conditions were created for DOPrKO mice, they could obtain morphineinduced CPP only after an increase in the number of conditioning sessions (eight sessions for KO mice $v s$ six sessions for WT controls). The latter results are also noteworthy because they argue against the notion that the 
lack of conditioning in DOPrKO mice could be attributed only to the anxiogenic phenotype described for these animals (Filliol et al, 2000; Nieto et al, 2005; Roberts et al, 2001). Apparently these animals showed lower ability for morphine-induced place conditioning even in the less anxiogenic environment, where they did not show any avoidance or preference. At the same time, the anxiogenic phenotype of DOPrKO is probably playing its role in the initial avoidance of the smooth floor by these animals and as in many cases with initial avoidance (Schenk et al, 1985; Carr et al, 1989; Swerdlow et al, 1989), one can speculate that any improvement following drug pairing with the nonpreferable conditions is not due to the rewarding, but to the anxiolytic properties of the drug.

Therefore, these results provide the first demonstration that the rewarding properties of morphine are decreased in DOPrKO mice. An attenuation of morphine place conditioning was also observed in WT mice that were pretreated with the DOPr antagonist NTI before morphine conditioning sessions, indicating that the observed reduction in the conditioned reinforcing effects of morphine is not the result of a developmental adaptation. These results are consistent with those of a previous report (Suzuki et al, 1994) in inbred ddY mice, showing that the DOPr antagonists (NTI, BNTX, and NTB) injected s.c. 20-30 min before conditioning abolished morphine-induced place preference. The efficacy of both DOPr1 and DOPr2 antagonists in preventing conditioning suggests that the activity of both receptor subtypes may necessary for the conditioning of morphine reward. The existence of DOPr subtypes has been suggested by a number of studies using the putative subtype-selective antagonists (Portoghese et al, 1992; Stewart and Hammond, 1993). However, this pharmacological evidence is in contradiction with the existence of only one DOPr clone. Probable existence of receptor complexes (dimers and/or heterodimers) can explain this contradiction. In addition, DOPrKO mice demonstrate little observable binding with DOPr1- and DOPr2-preferring radioligands (Zhu et al, 1999). In contrast to the results obtained in mice, the DOPr antagonist ICI, 174864 did not attenuate morphine-induced place conditioning in rats (Shippenberg et al, 1987). Species differences may account for the different results obtained. However, it is important to note that ICI, 174864 is a weak partial agonist at DOPr and its carboxypeptidase degradation product is a potent agonist of MOPr (Cohen et al, 1986).

Lenard et al (2007) reported recently that bivalent ligands containing an MOPr agonist pharmacophore connected to a DOPr antagonist pharmacophore through variable-length spacers (19-21 atoms) did not induce CPP as compared to morphine and an MOPr agonist MA-19. They also did not induce reinstatement in mice that previously had exhibited a place preference for morphine. These authors also tested the selective DOPr antagonist NTI with an attached spacer sequence of 20 atoms (DA-20) in combination with MA-19 and the resulting place preference was similar to that of MA-19 alone. Thus, it appears that MOPr/DOPr heterodimers, but not individual MOPr, may mediate the acquisition of morphine-induced place preference. The data shown in the present study cannot advocate decisively for the existence of MOPr/DOPr heterodimers. However, taken together with recent findings (Lenard et al, 2007), these data demonstrate that DOPr antagonism attenuates the conditioned reinforcing properties of morphine through interactions with MOPr.

The apparent difference between an enhancement of the contextual associations in the presence of morphine (sensitization) and a reduction of the contextual association in the absence of morphine (place preference) indicates that they probably depend on different neural substrates. Generally, the mesocorticolimbic DA system is indicated as a substrate of behavioral sensitization and reward. However, recent studies show that sensitization and conditioning are associated with different changes in drug-induced DA levels of the NAc shell and core (see Di Chiara and Bassareo, 2007 for review). Thus, morphinesensitized rats show augmentation of the drug-evoked DA in the NAc core and either no change or reduced response in the NAc shell. On the other hand, conditioned stimuli associated with morphine, increase DA in the NAc shell but not NAc core. The results of the present study may suggest that the neural circuits responsible for the development of behavioral sensitization and conditioned reward (likely NAc core and NAc shell) are different in respect to DOPr innervations and intricate interactions with the $\mathrm{DOPr}$ system. However, there is no data in the literature to support this notion. In addition, it should be noted that development of behavioral sensitization is a very indirect index of the abuse liability of the drug, whereas CPP (and self-administration) is a more direct manifestation of reward and abuse liability.

The present results raise important questions as to the role of MOPr and DOPr interactions in the development of sensitization to the locomotor-activating effects of morphine as well as in the morphine-induced conditioning. Fundamental questions also exist as to whether DOPr antagonists can attenuate the self-administration of morphine and other MOPr agonists. Elucidation of the biochemical and molecular mechanisms by which $\mathrm{MOPr} /$ DOPr interactions affect such important forms of druginduced long-term plasticity such as tolerance, sensitization, and dependence is clearly needed. In addition, the present data show that in both cases (CPP and locomotor sensitization) blockade of DOPr during the development phase was enough to disrupt behavior. This corresponds to the results of Heidbreder et al (1996) that DOPr are involved in the development but not expression of behavioral sensitization to cocaine. In the case of cocaine, initiation of behavioral sensitization is linked to the ventral tegmental area and its expression to the NAc (Kalivas, 1992). It remains to be determined whether the same relationship is true for morphine as well as the role of DOPr in each of these processes.

In conclusion, the present study demonstrates that morphine-induced context-dependent sensitization is enhanced and tolerance to the locomotor-activating effects of morphine is attenuated when DOPr function is blocked pharmacologically or genetically. Furthermore, the conditioning of morphine reward is attenuated. Together, these data indicate unique and contrasting roles of DOPr in the development and expression of long-term adaptations that occur in response to chronic MOPr agonist administration. Finally, these findings add to growing evidence that the development of MOPr agonists/DOPr antagonists may open 
new avenues for both the treatment and prevention of drug dependence and for the development of efficacious analgesics with reduced liability for abuse.

\section{ACKNOWLEDGEMENTS}

We thank Vicki Minney and Eric Oh for their excellent technical assistance.

\section{DISCLOSURE/CONFLICT OF INTEREST}

The authors declare that, except for income received from their primary employer, no financial support or compensation has been received from any individual or corporate entity over the past 3 years for research or professional service and there are no personal financial holdings that could be perceived as constituting a potential conflict of interest.

\section{REFERENCES}

Abdelhamid EE, Sultana M, Portoghese PS, Takemori AE (1991). Selective blockage of delta opioid receptors prevents the development of morphine tolerance and dependence in mice. J Pharmacol Exp Ther 258: 299-303.

Bailey CP, Connor M (2005). Opioids: cellular mechanisms of tolerance and physical dependence. Curr Opin Pharmacol 5: 60-68.

Cahill C M, Morinville A, Lee M C, Vincent J P, Collier B, Beaudet A (2001). Prolonged morphine treatment targets delta opioid receptors to neuronal plasma membranes and enhances delta-mediated antinociception. J Neurosci 21: 7598-7607.

Carr GD, Fibiger HC, Phillips AG (1989). Conditioned place preference as a measure of drug reward. In: Liebman JM, Cooper SJ (eds). Neuropharmacological Basis of Reward. Oxford Science Publications, Oxford, New York. pp 264-319.

Clarke S, Czyzyk T, Ansonoff M, Nitsche JF, Hsu MS, Nilsson L et al (2002). Autoradiography of opioid and ORL1 ligands in opioid receptor triple knockout mice. Eur J Neurosci 16: 1705-1712.

Cohen ML, Shuman RT, Osborne JJ, Gesellchen PD (1986). Opioid agonist activity of ICI 174864 and its carboxypeptidase degradation product, LY281217. J Pharmacol Exp Ther 238: 769-772.

Contet C, Filliol D, Matifas A, Kieffer BL (2007). Morphine-induced analgesic tolerance, locomotor sensitization and physical dependence do not require modification of mu opioid receptor, cdk5 and adenylate cyclase activity. Neuropharmacology 54: $475-486$.

Corbett AD, Henderson G, McKnight AT, Paterson SJ (2006). 75 years of opioid research: the exciting but vain quest for the Holy Grail. Br J Pharmacol 147(Suppl 1): S153-S162.

Cunningham CL, Niehus DR, Malott DH, Prather LK (1992). Genetic differences in the rewarding and activating effects of morphine and ethanol. Psychopharmacology (Berl) 107: 385-393.

Cunningham CL, Henderson CM, Bormann NM (1998). Extinction of ethanol-induced conditioned place preference and conditioned place aversion: effects of naloxone. Psychopharmacology (Berl) 139: 32-70.

Cunningham CL, Ferree NK, Howard MA (2003). Apparatus bias and place conditioning with ethanol in mice. Psychopharmacology (Berl) 170: 409-422.

Cunningham CL, Gremel CM, Groblewski PA (2006). Druginduced conditioned place preference and aversion in mice. Nat Protoc 1: 1662-1670.
Daniels DJ, Lenard NR, Etienne CL, Law PY, Roerig SC, Portoghese PS (2005). Opioid-induced tolerance and dependence in mice is modulated by the distance between pharmacophores in a bivalent ligand series. Proc Natl Acad Sci USA 102: 19208-19213.

Di Chiara G, Bassareo V (2007). Reward system and addiction: what dopamine does and doesn't do. Curr Opin Pharmacol 7: 69-76.

Eitan S, Bryant CD, Saliminejad N, Yang YC, Vojdani E, Keith Jr D et al (2003). Brain region-specific mechanisms for acute morphine-induced mitogen-activated protein kinase modulation and distinct patterns of activation during analgesic tolerance and locomotor sensitization. J Neurosci 23: 8360-8369.

Filliol D, Ghozland S, Chluba J, Martin M, Matthes HW, Simonin F et al (2000). Mice deficient for delta- and mu-opioid receptors exhibit opposing alterations of emotional responses. Nat Genet 25: 195-200.

Fundytus ME, Schiller PW, Shapiro M, Weltrowska G, Coderre TJ (1995). Attenuation of morphine tolerance and dependence with the highly selective delta-opioid receptor antagonist TIPP[psi]. Eur J Pharmacol 286: 105-108.

Gibaldi M, Perier D (1975). The trapezoid rule. In: Gibaldi M, Perier D (eds). Pharmacokinetics. Marcel Dekker: New York. pp 293-296.

Goody RJ, Oakley SM, Filliol D, Kieffer BL, Kitchen I (2002). Quantitative autoradiographic mapping of opioid receptors in the brain of delta-opioid receptor gene knockout mice. Brain Res 945: 9-19.

Gupta A, Decaillot FM, Devi LA (2006). Targeting opioid receptor heterodimers: strategies for screening and drug development. AAPS J 8: E153-E159.

Heidbreder CA, Goldberg SR, Shippenberg TS (1993). The kappaopioid receptor agonist U-69593 attenuates cocaine-induced behavioral sensitization in the rat. Brain Res 616: 335-338.

Heidbreder CA, Shippenberg TS (1994). U-69593 prevents cocaine sensitization by normalizing basal accumbens dopamine. Neuroreport 5: 1797-1800.

Heidbreder C, Shoaib M, Shippenberg TS (1996). Differential role of delta-opioid receptors in the development and expression of behavioral sensitization to cocaine. Eur J Pharmacol 298: 207-216.

Hyman SE (2005). Addiction: a disease of learning and memory. Am J Psychiatry 162: 1414-1422.

Jordan BA, Devi LA (1999). G-protein-coupled receptor heterodimerization modulates receptor function. Nature 399: 697-700.

Kalivas PW (1992). Neural substrate of sensitization to psychostimulants. Clin Neuropharmacol 15(Suppl 1 Part A): 648-649A.

Kornetsky C (2004). Brain-stimulation reward, morphine-induced oral stereotypy, and sensitization: implications for abuse. Neurosci Biobehav Rev 27: 777-786.

Law PY, Erickson-Herbrandson LJ, Zha QQ, Solberg J, Chu J, Sarre A et al (2005). Heterodimerization of mu- and delta-opioid receptors occurs at the cell surface only and requires receptor- $\mathrm{G}$ protein interactions. J Biol Chem 280: 11152-11164.

Lenard NR, Daniels DJ, Portoghese PS, Roerig SC (2007). Absence of conditioned place preference or reinstatement with bivalent ligands containing mu-opioid receptor agonist and delta-opioid receptor antagonist pharmacophores. Eur J Pharmacol 566: $75-82$.

Matthes HW, Maldonado R, Simonin F, Valverde O, Slowe S, Kitchen I et al (1996). Loss of morphine-induced analgesia, reward effect and withdrawal symptoms in mice lacking the muopioid-receptor gene. Nature 383: 819-823.

Miyamoto Y, Portoghese PS, Takemori AE (1993). Involvement of delta 2 opioid receptors in acute dependence on morphine in mice. J Pharmacol Exp Ther 265: 1325-1327.

Morinville A, Cahill CM, Esdaile MJ, Aibak H, Collier B, Kieffer BL et al (2003). Regulation of delta-opioid receptor trafficking via 
mu-opioid receptor stimulation: evidence from mu-opioid receptor knock-out mice. J Neurosci 23: 4888-4898.

Morinville A, Cahill CM, Kieffer B, Collier B, Beaudet A (2004). $\mathrm{Mu}$-opioid receptor knockout prevents changes in delta-opioid receptor trafficking induced by chronic inflammatory pain. Pain 109: $266-273$.

Narita M, Suzuki T, Funada M, Misawa M, Nagase H (1993). Involvement of delta-opioid receptors in the effects of morphine on locomotor activity and the mesolimbic dopaminergic system in mice. Psychopharmacology (Berl) 111: 423-426.

Nieto MM, Guen SL, Kieffer BL, Roques BP, Noble F (2005). Physiological control of emotion-related behaviors by endogenous enkephalins involves essentially the delta opioid receptors. Neuroscience 135: 305-313.

Nitsche JF, Schuller AG, King MA, Zengh M, Pasternak GW, Pintar JE (2002). Genetic dissociation of opiate tolerance and physical dependence in delta-opioid receptor-1 and preproenkephalin knock-out mice. J Neurosci 22: 10906-10913.

Portoghese PS, Sultana M, Takemori AE (1988). Naltrindole, a highly selective and potent non-peptide delta opioid receptor antagonist. Eur J Pharmacol 146: 185-186.

Portoghese PS, Sultana M, Nelson WL, Klein P, Takemori AE (1992). Delta opioid antagonist activity and binding studies of regioisomeric isothiocyanate derivatives of naltrindole: evidence for delta receptor subtypes. J Med Chem 35: 4086-4091.

Roberts AJ, Gold LH, Polis I, McDonald JS, Filliol D, Kieffer BL et al (2001). Increased ethanol self-administration in delta-opioid receptor knockout mice. Alcohol Clin Exp Res 25: 1249-1256.

Robinson TE, Berridge KC (1993). The neural basis of drug craving: an incentive-sensitization theory of addiction. Brain Res Brain Res Rev 18: 247-291.

Robinson TE, Berridge KC (2000). The psychology and neurobiology of addiction: an incentive-sensitization view. Addiction 95(Suppl 2): S91-S117.

Rozenfeld R, Abul-Husn NS, Gomez I, Devi LA (2007). An emerging role for the delta opioid receptor in the regulation of mu opioid receptor function. ScientificWorldJournal 7: 64-73.

Schenk S, Ellison F, Hunt T, Amit Z (1985). An examination of heroin conditioning in preferred and nonpreferred environments and in differentially housed mature and immature rats. Pharmacol Biochem Behav 22: 215-220.

Schenk S, Partridge B, Shippenberg TS (2001). Effects of the kappaopioid receptor agonist, U69593, on the development of sensitization and on the maintenance of cocaine self-administration. Neuropsychopharmacology 24: 441-450.

Schiller PW, Fundytus ME, Merovitz L, Weltrowska G, Nguyen TM, Lemieux C et al (1999). The opioid mu agonist/delta antagonist DIPP-NH(2)[Psi] produces a potent analgesic effect, no physical dependence, and less tolerance than morphine in rats. J Med Chem 42: 3520-3526.

Shippenberg TS, Bals-Kubik R, Herz A (1987). Motivational properties of opioids: evidence that an activation of deltareceptors mediates reinforcement processes. Brain Res 436: 234-239.

Simonin F, Slowe S, Becker JA, Matthes HW, Filliol D, Chluba J et al (2001). Analysis of [3H]bremazocine binding in single and combinatorial opioid receptor knockout mice. Eur J Pharmacol 414: 189-195.

Sora I, Takahashi N, Funada M, Ujike H, Revay RS, Donovan DM et al (1997). Opiate receptor knockout mice define mu receptor roles in endogenous nociceptive responses and morphineinduced analgesia. Proc Natl Acad Sci USA 94: 1544-1549.

Spanagel R, Shippenberg TS (1993). Modulation of morphineinduced sensitization by endogenous kappa opioid systems in the rat. Neurosci Lett 153: 232-236.

Stewart PE, Hammond DL (1993). Evidence for delta opioid receptor subtypes in rat spinal cord: studies with intrathecal naltriben, cyclic[D-Pen2, D-Pen5] enkephalin and [D-Ala2, Glu4]Deltorphin. J Pharmacol Exp Ther 266: 820-828.

Suzuki T, Yoshiike M, Mizoguchi H, Kamei J, Misawa M, Nagase H (1994). Blockade of delta-opioid receptors prevents morphine-induced place preference in mice. Jpn J Pharmacol 66: 131-137.

Swerdlow NR, Gilbert D, Koob GF (1989). Conditioned drug effects on spatial preference: critical evaluation. In: Boulton AA, Baker GB, Greenshaw AJ (eds). Psychopharmacology (Neuromethods Vol 13). Humana Press: Clifton. pp 399-446.

Timar J, Gyarmati Z, Furst Z (2005). The development of tolerance to locomotor effects of morphine and the effect of various opioid receptor antagonists in rats chronically treated with morphine. Brain Res Bull 64: 417-424.

Vanderschuren LJ, Everitt BJ (2005). Behavioral and neural mechanisms of compulsive drug seeking. Eur J Pharmacol 526: $77-88$.

Wells JL, Bartlett JL, Ananthan S, Bilsky EJ (2001). In vivo pharmacological characterization of SoRI 9409, a nonpeptidic opioid mu-agonist/delta-antagonist that produces limited antinociceptive tolerance and attenuates morphine physical dependence. J Pharmacol Exp Ther 297: 597-605.

Zernig G, Ahmed SH, Cardinal RN, Morgan D, Acquas E, Foltin RW et al (2007). Explaining the escalation of drug use in substance dependence: models and appropriate animal laboratory tests. Pharmacology 80: 65-119.

Zhu Y, King MA, Schuller AG, Nitsche JF, Reidl M, Elde RP et al (1999). Retention of supraspinal delta-like analgesia and loss of morphine tolerance in delta opioid receptor knockout mice. Neuron 24: 243-252. 